\title{
VENTILATORY CAPACITY AND EXERCISE VENTILATION IN CONGENITAL AND ACQUIRED CARDIAC DISEASE
}

\author{
BY \\ GRAEME SLOMAN AND BRYAN GANDEVIA* \\ From Cardiac Department and University Department of Medicine, Royal Melbourne Hospital, Melbourne, Victoria, \\ Australia
}

Received March 4, 1963

In some forms of cardiac disease an abnormally high ventilatory response to exercise contributes to the production of disability and impairment of exercise tolerance (Campbell, 1934). In this paper we record the results of a standardized exercise test, relating ventilatory response to the work done, in a series of 163 patients with congenital and acquired cardiac disease. The findings are considered in relation to measurements of ventilatory capacity and to the parameters of circulatory function assessed during routine right and left heart catheterization.

\section{Patients AND Methods}

The series consists of patients capable of exercise referred to the Cardiac Clinic at the Royal Melbourne Hospital for investigation of congenital or valvular heart disease over a period of nine months in 1959-1960. The series is selective, in that patients were often referred because of diagnostic difficulty, the comparative rarity of the cardiac lesion, or the possibility of surgical assistance. Patients with associated severe pulmonary disease, unless clinically unrecognized, were excluded. The series comprises 76 men and 86 women. The final diagnoses, with the relevant data, are set out in the Table, where they are shown in five major groups.

1. Valvular disease, predominantly or wholly affecting the mitral valve (67 cases); in 8 cases mitral regurgitation was the chief functional abnormality, and associated aortic lesions were present in 10 cases.

2. Valvular disease, predominantly or wholly affecting the aortic valve ( 28 cases): all were predominantly stenotic, and only 3 had significant regurgitation.

3. Left-to-right shunts (37 cases), comprising atrial septal defect, 22 cases; patent ductus arteriosus, 7; ventricular septal defect, 3; anomalous pulmonary venous drainage, 2; aorto-pulmonary defect, 2; combined ventricular septal defect and patent ductus, 1 .

4. Pulmonary stenosis (14 cases).

5. Miscellaneous conditions (17 cases), including several patients in whom a diagnosis of congenital or valvular heart disease was ultimately excluded.

Before the ventilatory tests were done, exercise tolerance was assessed by one of us (G.S.) using the following scale.

Grade 0. Athletic or taking an active part in competitive sport without apparent disability.

Grade I. Normal or able to keep up with others of the same age and sex walking up hills and stairs.

Grade II. Unable to keep up with others of the same age walking up hills and stairs, but able to keep up on the flat at an average pace.

Grade III. Unable to keep up on the flat but able to walk 'indefinitely' (for 15 minutes or half a mile) on the flat at own pace.

Grade IV. Unable to walk half a mile or for 15 minutes on the flat at own pace without a rest.

The exercise test was basically that described by Hugh-Jones (1952) but the calculations and the derived index of ventilatory requirement differed (Gandevia, 1962). The subject climbed up and down steps at a

* Present address: Department of Medicine, Prince Henry Hospital and University of New South Wales, Sydney, Australia. 
steady rate for five minutes, the work performed being controlled by adjusting the step height and rate of stepping according to the patient's weight. The actual work level chosen was varied according to the patient's exercise tolerance. Ventilation was measured with a Wright ventilometer at rest, during the exercise, and during recovery. The excess ventilation, over and above the resting level, during both exercise and recovery phases, was calculated and then divided by the work done. This gives a figure, in litres of ventilation per kilogram-metre per minute which is independent of the work level employed. Multiplying by 300 indicates the excess ventilation in litres per minute required by the subject if exercised at 300 kilogrammetres per minute; this level was chosen arbitrarily because it is close to the work level that we commonly employ and it has, in fact, been used routinely in similar studies (Stock and Kennedy, 1953, 1959). As in Hugh-Jones' original method, the resting ventilation is added to the excess ventilation to give the standardized ventilation ( $\mathrm{SV}_{300}$, the work level being indicated by the subscript). The advantage of the present method of calculation is that it allows comparison of subjects exercised at different work levels by 'adjusting' the standardized ventilation to a standard work level. The method has been described and its validity examined in a previous paper (Gandevia, 1962), where it was also shown that the effects of sex and age on standardized ventilation were negligible in normal subjects. The normal value in this laboratory is $29 \pm 5$ litres per minute. The work level for each patient was such that it would produce moderate stress but would not be so severe that at least four minutes of exercise could not be completed. If the work level is too low psychological hyperventilation may occur (Gandevia, 1962), whereas if less than four minutes of exercise is completed we have observed that the results show poor reproducibility. Tests that did not conform to these requirements were repeated at a different work level. In general, work levels of 350,250 , or 125 kilogram-metres per minute were used for patients with disability Grades 0-I, Grades II-III, and Grade IV respectively: small women were not exercised above 250 kilogram-metres per minute. Occasionally very severely disabled patients were allowed to choose their own stepping rate when a level of 125 kilogrammetres per minute was considered too strenuous.

Ventilatory capacity was assessed from a forced expiratory spirogram recorded with a low resistance spirometer; and the forced expiratory volume at one second $\left(\mathrm{FEV}_{1}\right)$ was read off with a scaled transparent protractor. The vital capacity (VC) was estimated in the conventional manner from an unhurried expiration. For both $\mathrm{FEV}_{1}$ and $\mathrm{VC}$ the highest reading from several attempts was accepted, with the proviso that three readings should show agreement within 10 per cent. In this paper it suffices to express FEV $_{1}$ and VC as a percentage of the normal value calculated according to sex and height $\left(\mathrm{FEV}_{1} \% \mathrm{~N} ; \mathrm{VC} \% \mathrm{~N}\right) . \quad$ All gas volumes are expressed as volumes at body temperature, ambient pressure, and saturated with water vapour; room temperatures ranged from $18^{\circ} \mathrm{C}$. to $24^{\circ} \mathrm{C}$.

When cardiac catheterization studies were carried out the patients were lightly sedated and fasting. An antecubital or great saphenous vein was used for right heart studies and the right brachial or femoral artery for left heart investigation. Pressures were obtained with a Sanborn transducer. Blood oxygen saturation was measured with a Brinkmann hæmoreflector.

\section{RESULTS}

The mean values for $\mathrm{SV}_{300}, \mathrm{FEV}_{1} \% \mathrm{~N}$, and $\mathrm{VC} \% \mathrm{~N}$ in the entire series are set out in the Table according to sex and exercise tolerance grade. In general the results for men and women are similar and the trends identical. By combining the sexes for the two indices of ventilatory capacity (a procedure justified by the method of calculation which takes sex into account) and recalculating means, the results may be shown in simple schematic form (Fig. 1). The mean $\mathrm{SV}_{300}$ increases with decreasing exercise tolerance, although the difference between the means for Grade $\mathrm{O}$ and Grade I (both of which are 'normal') is negligible. The differences in mean $\mathrm{SV}_{300}$ for Grades I and III subjects are statistically significant* in both sexes, but between Grades III and IV the difference is significant only for women. $\mathrm{FEV}_{1} \% \mathrm{~N}$ and $\mathrm{VC} \% \mathrm{~N}$ show little change between Grades 0 and III, although the difference between Grades $\mathrm{O}$ and $\mathrm{I}$ is significant in the women, but $\mathrm{VC} \% \mathrm{~N}$ and particularly $\mathrm{FEV}_{1} \% \mathrm{~N}$ show a profound and significant fall between Grade III and Grade IV patients.

The disproportionate fall in $\mathrm{FEV}_{1}$ compared with the $\mathrm{VC}$ between these Grades was reflected in a reduced value for the ratio $\frac{\mathrm{FEV}_{1} \times 100}{\mathrm{VC}}$. The concomitant changes in ventilatory capacity and

* Throughout this paper 'significance' implies $\mathrm{p}<0.02$. As the method of grading exercise tolerance, and hence of subdividing the series, is subjective and by no means rigid, the presence or absence of significant percentage differences has little absolute validity. 
TABLE

Standardized Ventilation, Forced Expiratory Volume, and Vital Capacity in 163 Patients with Valvular DISEASES

\begin{tabular}{|c|c|c|c|c|c|c|c|c|c|c|}
\hline & \multicolumn{2}{|c|}{ No. of cases } & \multicolumn{2}{|c|}{ Age } & \multicolumn{2}{|c|}{$\mathbf{S V}_{300}$} & \multicolumn{2}{|c|}{$\mathrm{FEV}_{1} \% \mathrm{~N}$} & \multicolumn{2}{|c|}{$\mathrm{VC} \% \mathrm{~N}$} \\
\hline & Male & Female & Male & Female & Male & Female & Male & Female & Male & Female \\
\hline $\begin{array}{c}\text { Mitral valve disease } \\
\text { Grade } 0 \text { and I } \\
\text { II } \\
\text { III } \\
\text { IV }\end{array}$ & $\begin{array}{l}4 \\
8 \\
7 \\
3\end{array}$ & $\begin{array}{r}5 \\
17 \\
17 \\
6\end{array}$ & $\begin{array}{l}25 \cdot 8 \\
(7 \cdot 5) \dagger \\
41 \cdot 9 \\
(8 \cdot 2) \\
41 \cdot 6 \\
(6 \cdot 3) \\
43 \cdot 3 \\
(8 \cdot 6)\end{array}$ & $\begin{array}{l}29 \cdot 0 \\
(9 \cdot 3) \\
38 \cdot 8 \\
(6 \cdot 7) \\
38 \cdot 5 \\
(7 \cdot 1) \\
44 \cdot 5 \\
(9 \cdot 8)\end{array}$ & $\begin{array}{l}35 \cdot 2 \\
(7 \cdot 8) \\
41 \cdot 9 \\
(6 \cdot 0) \\
53 \cdot 6 \\
(18 \cdot 7) \\
57 \cdot 2 \\
(7 \cdot 6)\end{array}$ & $\begin{array}{l}29 \cdot 9 \\
(2 \cdot 8) \\
38.9 \\
(14 \cdot 8) \\
41 \cdot 3 \\
(14 \cdot 3) \\
49 \cdot 7 \\
(11 \cdot 0)\end{array}$ & $\begin{array}{c}112 \cdot 2 \\
(6 \cdot 3) \\
96 \cdot 0 \\
(21 \cdot 2) \\
84 \cdot 6 \\
(28 \cdot 3) \\
80 \cdot 7 \\
(3 \cdot 9)\end{array}$ & $\begin{array}{l}102 \cdot 8 \\
(45 \cdot 0) \\
102 \cdot 2 \\
(22 \cdot 7) \\
105 \cdot 2 \\
(24 \cdot 3) \\
9 \cdot 5 \\
(27 \cdot 1)\end{array}$ & $\begin{array}{l}113 \cdot 6 \\
(12 \cdot 3) \\
95 \cdot 9 \\
(17 \cdot 1) \\
92 \cdot 1 \\
(23 \cdot 9) \\
72 \cdot 6 \\
(4 \cdot 3)\end{array}$ & $\begin{array}{l}98 \cdot 6 \\
(9 \cdot 7) \\
106.9 \\
(21 \cdot 0) \\
101 \cdot 6 \\
(20.9) \\
89.5 \\
(15.4)\end{array}$ \\
\hline $\begin{array}{c}\begin{array}{c}\text { Aortic valve disease } \\
\text { Grade } 0 \text { and I }\end{array} \\
\text { II } \\
\text { III } \\
\text { IV }\end{array}$ & $\begin{array}{r}10 \\
6 \\
7\end{array}$ & $\begin{array}{c}- \\
2 \\
1\end{array}$ & $\begin{array}{l}39 \cdot 9 \\
(8 \cdot 1) \\
37 \cdot 5 \\
(5 \cdot 7) \\
5 \cdot 5 \\
(8 \cdot 3) \\
53 \cdot 0 \\
-\end{array}$ & $\begin{array}{l}\overline{-} \\
49 \cdot 5 \\
(4 \cdot 9) \\
55 \\
\frac{47}{-}\end{array}$ & $\begin{array}{l}33 \cdot 8 \\
(7 \cdot 8) \\
31 \cdot 8 \\
(8 \cdot 4) \\
38.7 \\
(7.9) \\
71 \\
-\end{array}$ & $\begin{array}{l}\overline{7} \\
31 \cdot 9 \\
(7 \cdot 1) \\
41 \cdot 8 \\
\overline{44 \cdot 2} \\
-\end{array}$ & $\begin{array}{l}106 \cdot 0 \\
(25 \cdot 4) \\
91 \cdot 4 \\
(22 \cdot 8) \\
92 \cdot 7 \\
(38 \cdot 2) \\
62 \cdot 5 \\
-\end{array}$ & $\begin{array}{l}\overline{-} \\
\overline{90 \cdot 0} \\
(14 \cdot 1) \\
111 \cdot 1 \\
\overline{80 \cdot 0} \\
-\end{array}$ & $\begin{array}{l}103 \cdot 4 \\
(16 \cdot 9) \\
97 \cdot 5 \\
(12 \cdot 6) \\
106 \cdot 8 \\
(28 \cdot 3) \\
86 \cdot 1 \\
-\end{array}$ & $\begin{array}{l}\overline{-} \\
82 \cdot 9 \\
(8 \cdot 5) \\
96 \cdot 3 \\
\overline{121 \cdot 4} \\
-\end{array}$ \\
\hline $\begin{array}{l}\text { Left-to-right shunt } \\
\text { Grade } 0 \text { and I } \\
\qquad \begin{array}{c}\text { II } \\
\text { III } \\
\text { IV }\end{array}\end{array}$ & $\begin{array}{r}12 \\
2 \\
1\end{array}$ & $\begin{array}{l}9 \\
4\end{array}$ & $\begin{array}{l}23 \cdot 8 \\
(8 \cdot 6) \\
44 \cdot 0 \\
(2 \cdot 8) \\
38 \cdot 0 \\
= \\
=\end{array}$ & $\begin{array}{c}27 \cdot 0 \\
(9 \cdot 0) \\
36 \cdot 0 \\
(12 \cdot 1) \\
39 \cdot 5 \\
(14 \cdot 9) \\
53 \cdot 6 \\
(20 \cdot 8)\end{array}$ & $\begin{array}{l}30 \cdot 5 \\
(7 \cdot 2) \\
47 \cdot 8 \\
(13 \cdot 6) \\
34 \cdot 3 \\
= \\
=\end{array}$ & $\begin{array}{l}26 \cdot 9 \\
(8 \cdot 9) \\
33 \cdot 5 \\
(9 \cdot 5) \\
30 \cdot 3 \\
(5 \cdot 1) \\
45 \cdot 9 \\
(41 \cdot 3)\end{array}$ & $\begin{array}{c}102 \cdot 7 \\
(21 \cdot 9) \\
93 \cdot 7 \\
(115 \cdot 2) \\
104 \cdot 0 \\
= \\
=\end{array}$ & $\begin{array}{c}103 \cdot 7 \\
(32 \cdot 5) \\
95 \cdot 4 \\
(30 \cdot 8) \\
86 \cdot 4 \\
(15 \cdot 9) \\
63 \cdot 1 \\
(5 \cdot 1)\end{array}$ & $\begin{array}{c}102 \cdot 6 \\
(22 \cdot 0) \\
96 \cdot 1 \\
(9 \cdot 0) \\
121 \cdot 9 \\
= \\
=\end{array}$ & $\begin{array}{l}102 \cdot 7 \\
(12 \cdot 3) \\
93 \cdot 3 \\
(22 \cdot 1) \\
79 \cdot 7 \\
(14 \cdot 2) \\
94 \cdot 1 \\
(48 \cdot 5)\end{array}$ \\
\hline $\begin{array}{c}\text { Pulmonary stenosis } \\
\text { Grade } 0 \text { and I } \\
\text { II } \\
\text { III }\end{array}$ & $\begin{array}{l}2 \\
2\end{array}$ & $\begin{array}{l}3 \\
3\end{array}$ & $\begin{array}{c}52 \cdot 0 \\
(4 \cdot 0) \\
32 \cdot 0 \\
(17 \cdot 0) \\
= \\
-\end{array}$ & $\begin{array}{c}17.0 \\
(5.0) \\
33.0 \\
(13.7) \\
30.5 \\
(7 \cdot 7)\end{array}$ & $\begin{array}{l}36 \cdot 7 \\
(8 \cdot 5) \\
39 \cdot 2 \\
(6 \cdot 6) \\
=\end{array}$ & $\begin{array}{c}29 \cdot 3 \\
(13 \cdot 0) \\
40 \cdot 8 \\
(19 \cdot 6) \\
35 \cdot 9 \\
(12 \cdot 0)\end{array}$ & $\begin{array}{c}79 \cdot 0 \\
(29 \cdot 8) \\
120 \cdot 1 \\
(31 \cdot 3) \\
=\end{array}$ & $\begin{array}{l}106 \cdot 0 \\
(17 \cdot 8) \\
126 \cdot 1 \\
(26 \cdot 1) \\
93 \cdot 4) \\
(30 \cdot 1)\end{array}$ & $\begin{array}{c}103 \cdot 4 \\
(4 \cdot 8) \\
111 \cdot 2 \\
(2 \cdot 2) \\
=\end{array}$ & $\begin{array}{l}99 \cdot 5 \\
(15 \cdot 1) \\
113 \cdot 1 \\
(12 \cdot 9) \\
93 \cdot 2 \\
(27 \cdot 1)\end{array}$ \\
\hline $\begin{array}{c}\text { * Miscellaneous } \\
\text { conditions } \\
\text { Grade 0 and I } \\
\text { II } \\
\text { III } \\
\text { IV }\end{array}$ & $\begin{array}{l}2 \\
1 \\
5 \\
3\end{array}$ & $\begin{array}{l}2 \\
1 \\
2 \\
-\end{array}$ & $\begin{array}{l}24 \cdot 2 \\
34 \cdot 5 \\
38 \cdot 6 \\
55 \cdot 2\end{array}$ & & $\begin{array}{l}28 \cdot 7 \\
43 \cdot 3 \\
57 \cdot 7 \\
63 \cdot 0\end{array}$ & & $\begin{array}{r}103 \cdot 4 \\
103 \cdot 5 \\
96 \cdot 0 \\
86 \cdot 5\end{array}$ & & $\begin{array}{r}109 \cdot 5 \\
103 \cdot 9 \\
100 \cdot 2 \\
69 \cdot 6\end{array}$ & \\
\hline
\end{tabular}

* Only average values, without distinction of sex, are quoted in view of the variety of conditions included.

$\dagger$ The figures in brackets give the standard deviation for each parameter.

standardized ventilation are reflected in the several 'dyspnœic indices' relating these two parameters, which have been described but appear to us to have no advantage over visual inspection of the individual results.

Thus, increased disability in the present series of patients, with a variety of forms of congenital and acquired cardiac disease, was associated with a progressive rise in ventilatory requirement for exercise and with the development of an obstructive ventilatory defect in the more severely disabled patients. In the latter group the concomitant reduction in VC suggests that a restrictive ventilatory defect is also present. 


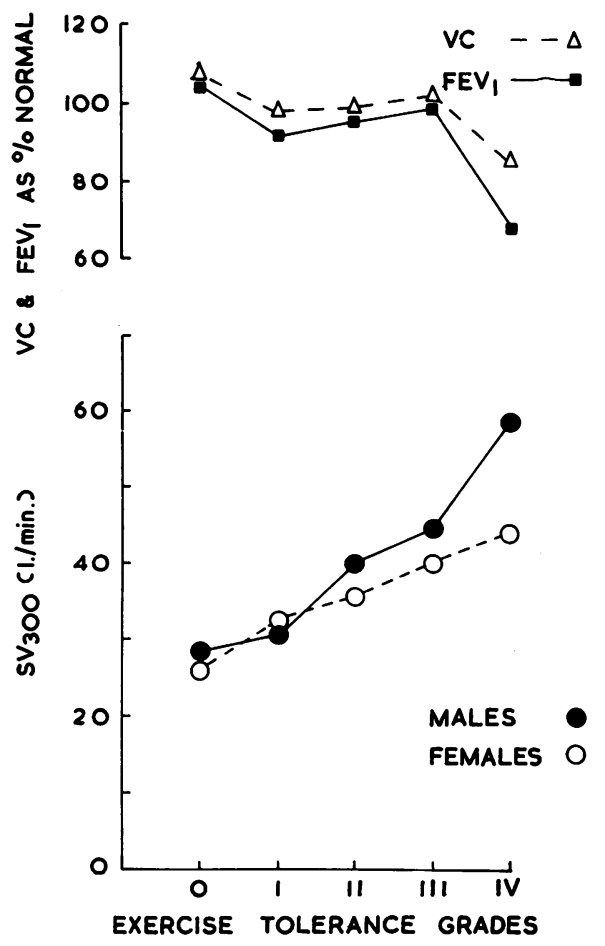

FIG. 1.-Mean values (men and women) for $\mathrm{SV}_{300}$ and ventilatory capacity indices (sexes combined) for five gradings of exercise tolerance.

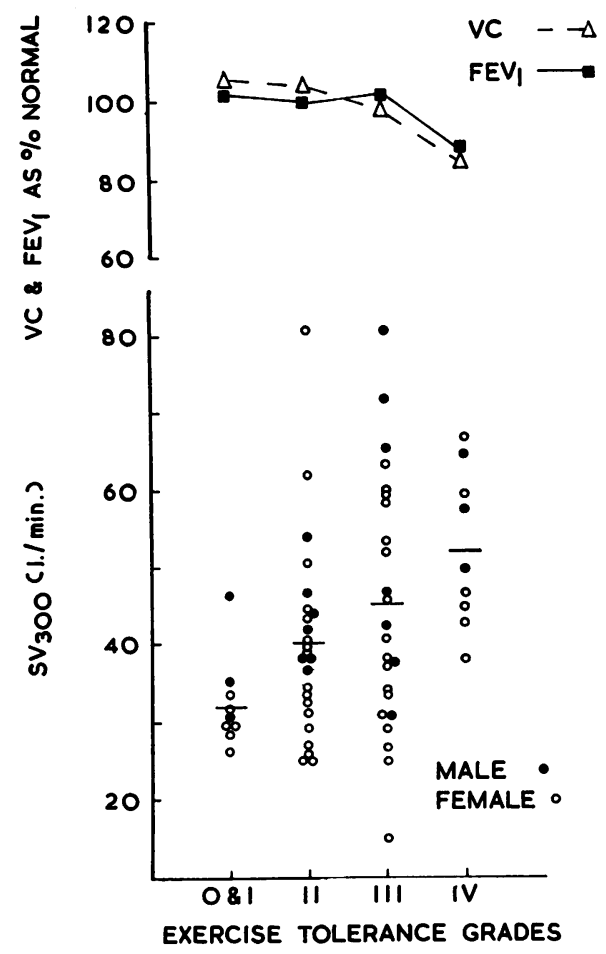

Frg. 2.-Mitral valve disease: values for $\mathbf{S V}_{300}$ and mean values for ventilatory capacity indices for four gradings of exercise tolerance (Grades $\mathbf{0}$ and I are combined).

\section{Mitral Valve Disease}

The results for patients with mitral valve disease are summarized in Fig. 2. Grade 0 and Grade I are combined, as both indicate a 'normal' exercise tolerance and the values showed no significant differences. A similar trend towards rising exercise ventilatory requirement with increasing grade of disability is found (statistically significant as between the normal group and those with Grade III disability), together with a decrease in ventilatory capacity in the patients with Grade IV disability.

Relation between $S V_{300}$ and Hamodynamic Data. When the $\mathrm{SV}_{300}$ is plotted against the resting cardiac output in the 30 patients subjected to right heart catheterization, there is a suggestive relation (Fig. 3), such that those with lower cardiac output tend to have a higher $\mathrm{SV}_{300}$, but the correlation coefficient fails to reach the 5 per cent of significance $(r=-0.331)$.

Significant correlation is found between $\mathrm{SV}_{300}$ and resting systolic or mean pulmonary artery pressure $(r=0.420$ and 0.443 respectively) (Fig. 4), pulmonary vascular resistance $(r=0.451)$ (Fig. 5), and mean left atrial pressure $(r=0 \cdot 368)$ (Fig. 6).

\section{Aortic Valve Disease}

In aortic valve disease any increase in $\mathrm{SV}_{300}$ with decreasing exercise tolerance is much less apparent, and the reduction in ventilatory capacity, although considerable in relation to $\mathrm{FEV}_{1}$, is determined in Grade IV by only two patients (Fig. 7).

Relation between $S V_{300}$ and Hamodynamic Data. In the 15 patients in whom left heart catheterization was performed no correlation was apparent between $\mathrm{SV}_{300}$ and resting left ventricular systolic pressure, aortic diastolic pressure, pulse pressure, or systolic gradient across the aortic valve. 


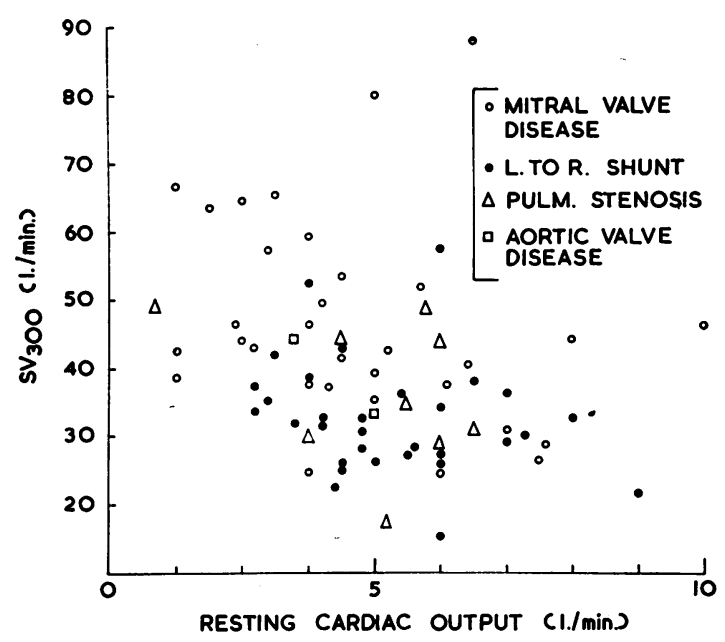

FIG. 3.-Resting cardiac output plotted against $\mathrm{SV}_{\mathbf{3 0 0}}$ for patients with mitral valve disease, aortic valve disease, left-to-right shunts, and pulmonary stenosis.

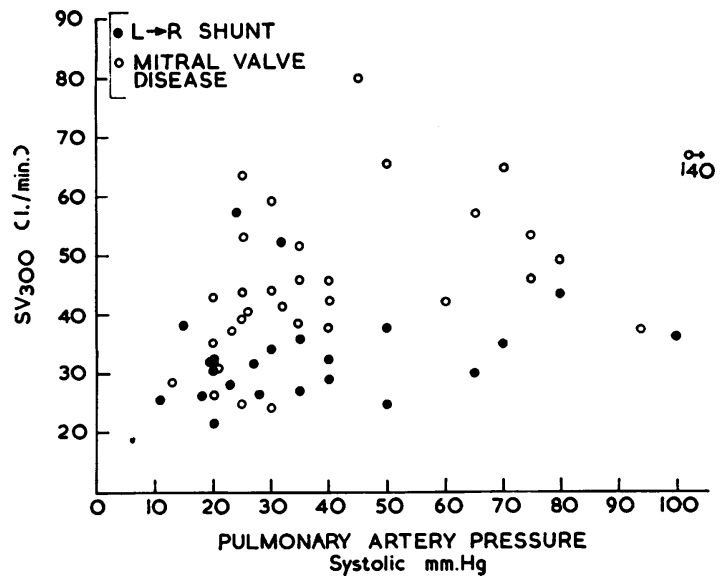

FIG. 4.-Resting systolic pulmonary arterial pressure plotted against $\mathrm{SV}_{300}$ for patients with mitral valve disease and left-to-right shunts.

\section{Left-to-right Shunt}

No rise in $\mathrm{SV}_{300}$ with decreasing exercise tolerance is demonstrable (Fig. 8), but the trend towards a decrease in the indices of ventilatory capacity, notably $\mathrm{FEV}_{1}$, is still present.

Relation between $S V_{300}$ and Hamodynamic Data. There is no significant correlation between $\mathrm{SV}_{300}$ and resting systemic blood flow $(\mathrm{r}=-0 \cdot 317)$ (Fig. 3), pulmonary arterial pressure (Fig. 4), or pulmonary vascular resistance (Fig. 5), although the latter was slightly raised in this series. No significant correlation is found between $\mathrm{SV}_{300}$ and pulmonary blood flow in the seven cases in which this was estimated $(r=-0.716)$ (Fig. 9), although the trend may be suggestive. When the $\mathrm{SV}_{\mathbf{3 0 0}}$ is plotted against pulmonary flow expressed as a proportion of systemic flow, only a random scatter of points is found.

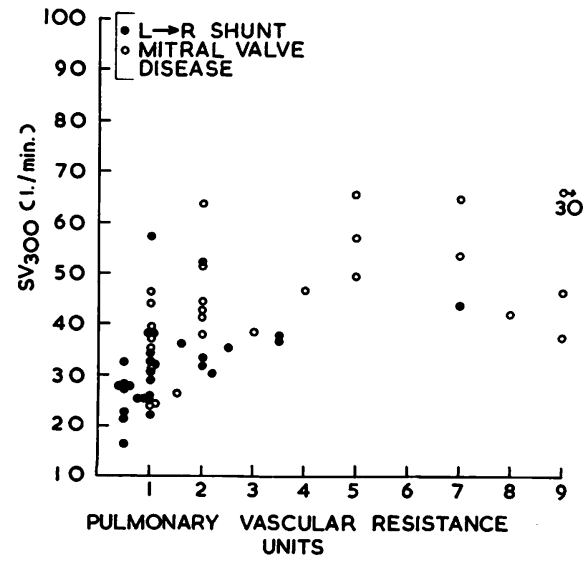

FIG. 5.-Resting pulmonary vascular resistance plotted against $\mathbf{S V}_{\mathbf{3 0}}$ for patients with mitral valve disease and left-to-right shunts.

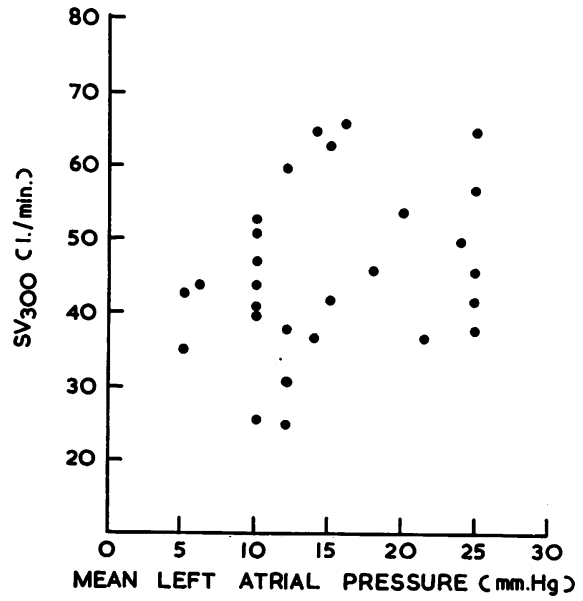

Fro. 6.-Resting mean left atrial pressure plotted against $\mathbf{S V}_{300}$ in mitral valve disease. 


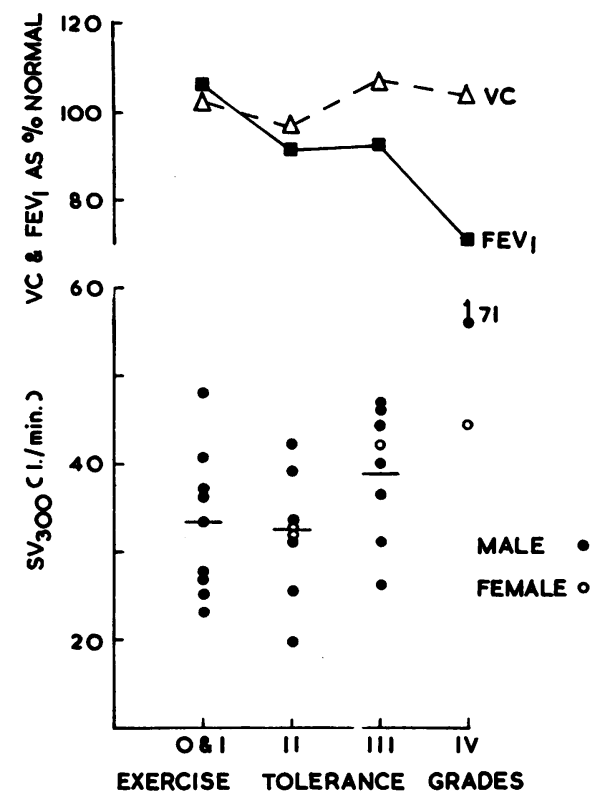

FIG. 7.-Aortic valve disease: values for $\mathrm{SV}_{300}$ and mean values for ventilatory capacity indices for four exercise tolerance grades (Grades 0 and I are combined).

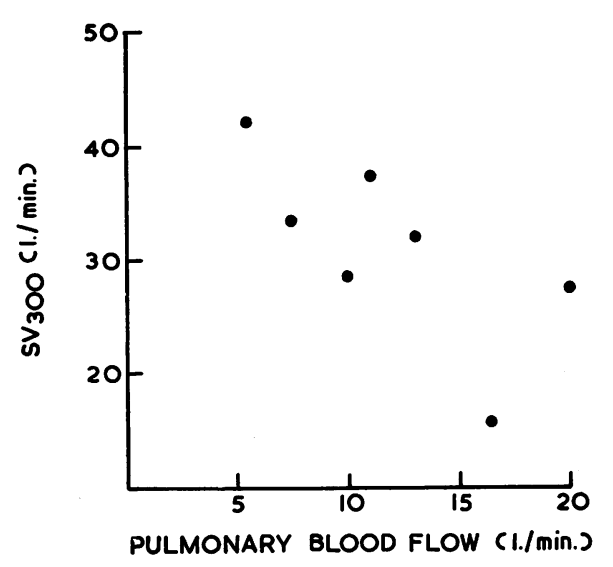

Fig. 9.-Resting pulmonary blood flow plotted against $\mathrm{SV}_{\mathbf{3 0 0}}$ in patients with a left-to-right shunt.

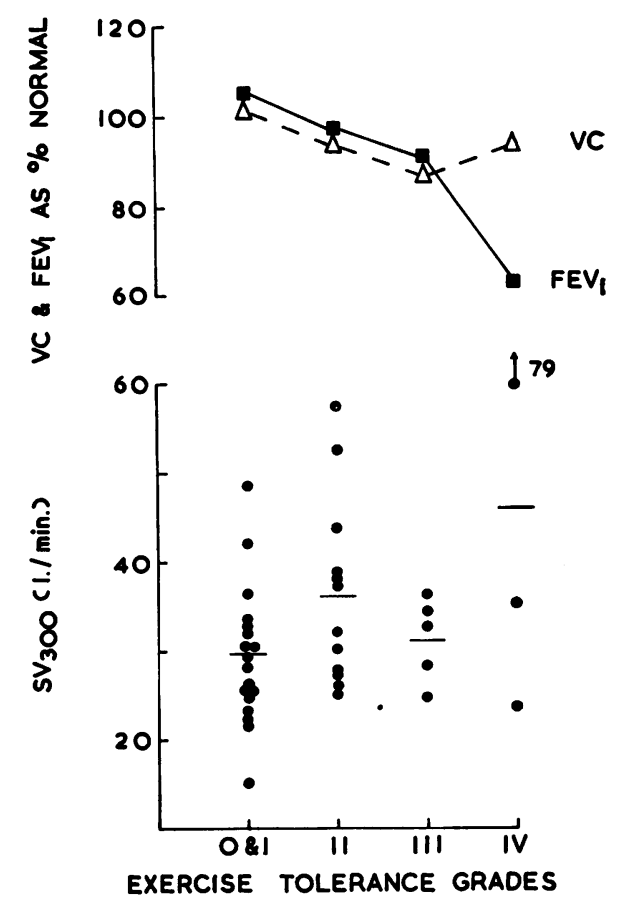

Fig. 8.-Left-to-right shunt: values for $\mathrm{SV}_{300}$ and mean values for ventilatory capacity indices for four exercise tolerance grades (Grades 0 and I are combined).
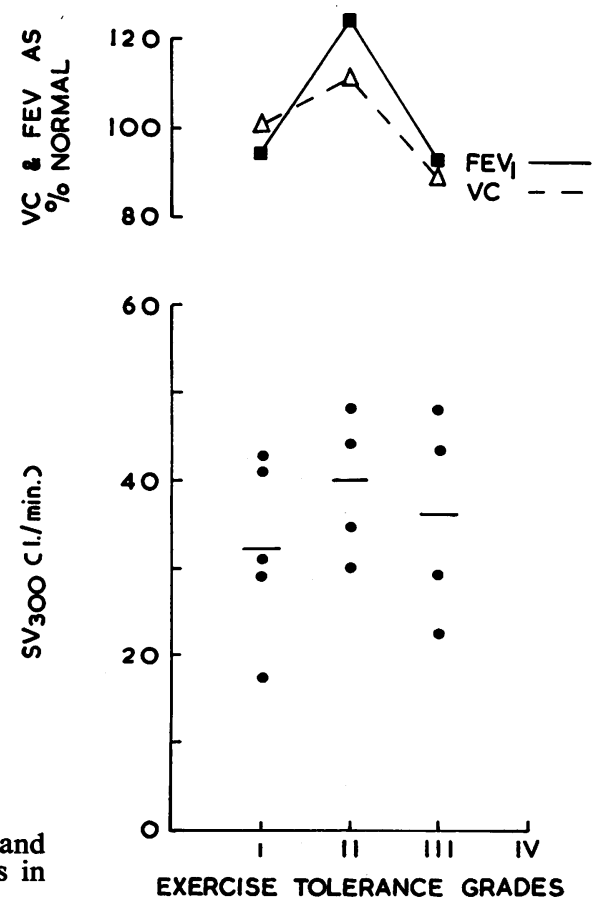

Fig. 10.-Pulmonary stenosis: values for $\mathrm{SV}_{\mathbf{3 0 0}}$ and mean values for ventilatory capacity indices in three exercise tolerance grades. 


\section{Pulmonary Stenosis}

The results in the 14 cases of pulmonary stenosis show no consistent pattern (Fig. 10): however, no patients with Grade IV disability were studied.

Relation between $S V_{300}$ and Hamodynamic Data. No correlation is demonstrable between $\mathrm{SV}_{300}$ and resting cardiac output $(\mathrm{r}=-0 \cdot 282)$ (Fig. 3) nor between $\mathrm{SV}_{300}$ and right ventricular peak systolic pressure.

\section{Miscellaneous Group}

The results according to diagnosis are shown in Fig. 11. The pattern of rising $\mathrm{SV}_{300}$ with increasing grade of effort intolerance is found with a decrease in ventilatory capacity in the most disabled group. The series is too small to warrant comment on the individual disorders, although it may be noted that two of the highest values for $\mathrm{SV}_{300}$ in the series were recorded in patients with coronary artery disease and clinical evidence of left ventricular failure.

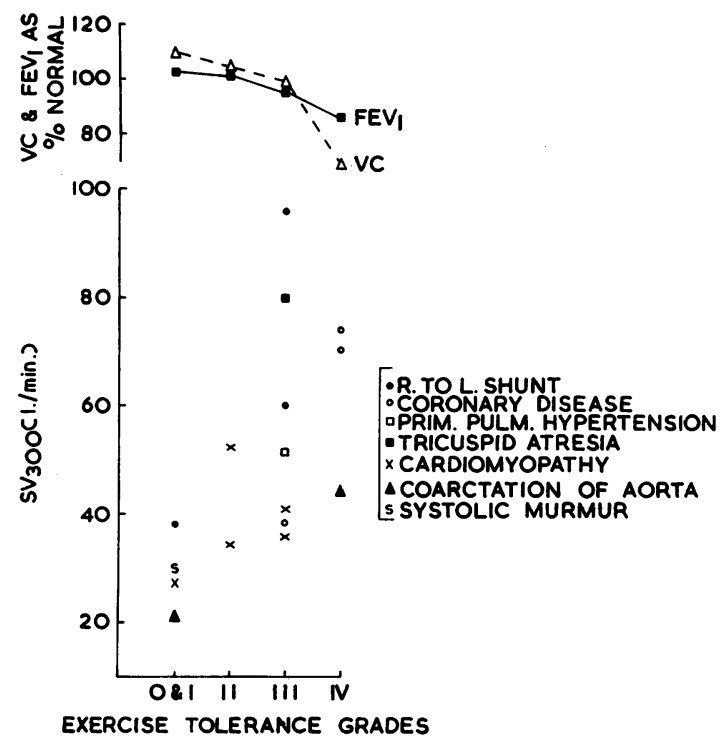

FIG. 11.-Miscellaneous conditions: values for $\mathrm{SV}_{300}$ and mean values for ventilatory capacity indices in four exercise tolerance grades (Grades 0 and $I$ are combined).

\section{Discussion}

This study was planned as a preliminary survey to provide basic information to help in designing further studies of cardio-respiratory function during exercise. To our knowledge, no comparable data on ventilatory requirements for a standard or known amount of exercise have been published for cardiac disorders other than mitral valve disease, where the abnormally high ventilatory demands on exercise are well documented (Stock and Kennedy, 1953, 1959).

Taking the series as a whole, the results suggest that an increased ventilatory response to exercise contributes significantly to impairment of exercise tolerance. Assessment of the latter in the present study was largely subjective, and this is doubtless a partial explanation of the wide scatter of values obtained for the values for $\mathrm{SV}_{300}$ within a given exercise tolerance grade: in fact, one advantage of an exercise test in patients with cardiac disease is that it offers some opportunity for objective assessment of exercise capacity. It is our impression that disability is more frequently overestimated by cardiac patients than by patients with chronic pulmonary disease, an observation that probably reflects the popular view that exercise is hazardous for patients with 'heart trouble'. In view of the method of assessing tolerance, it is not justifiable to attribute the scatter of $S V_{300}$ values within any exercise tolerance grade simply to the existence of two groups of patients, one limited by excessive ventilatory requirements and the other by circulatory factors, even though this concept may have some validity (Wyndham and Ward, 1957). Our findings suggest that in more disabled patients of all diagnostic groups, except pulmonary stenosis, there is also some impairment of ventilatory capacity, which is obstructive as well as restrictive in type. Mean values and ranges quoted by Friedman, Macias, and Yu (1959) for the 'timed vital capacity' at one second, the air velocity index, and vital capacity in 45 cases of mitral stenosis are in accord with this finding, although their results do not reach statistical significance. Stock and Kennedy (1953), studying patients with mitral stenosis and using a similar exercise test, found a progressive decrease in ventilatory capacity with increasing disability as well as a progressive increase in $\mathbf{S V}_{300}$. Our findings differ only in that we observed little or no fall in the vital capacity or forced expiratory volume at one second 
until the patients were severely disabled: the difference may reflect a greater prevalence of significant bronchitis in the British population. Nearly one-third of the patients with mitral valve disease showed a significant increase (over $10 \%$ ) in $\mathrm{FEV}_{1}$ after a bronchodilator ærosol (Gandevia and Rogers, 1963).

Analysis of the data according to diagnosis indicates that the increase in exercise ventilation is most obvious in mitral valve disease, less so with aortic lesions, virtually absent with left-to-right shunts, and apparently inconsistent in patients with pulmonary stenosis. Furthermore, any demonstrable relation between standardized ventilation and the several hæmodynamic parameters measured at rest in this study is not close, although better correlation might well be found with measurements during exercise. In one patient in whom reversal of a left-to-right shunt occurred on exercise at $\mathbf{2 5 0}$ kilogram-metres per minute, we constantly observed a disproportionate increase in ventilatory requirements above this work level.

Stock and Kennedy (1959) found, in patients with mitral stenosis, significant correlations between exercise ventilatory requirement and resting pulmonary capillary pressure, 'mitral index', and pulmonary vascular resistance, and our results confirm these observations. In view of the absence of correlation of $\mathrm{SV}_{300}$ with cardiac output in our patients with pulmonary stenosis, and the complexity of the physiological responses to exercise in mitral stenosis, it seems preferable to relate the abnormal ventilatory response in the latter condition, not simply to limitation of cardiac output, but more loosely to overall disturbance of cardiopulmonary hæmodynamics. Indeed, perhaps the most significant conclusion to be drawn from our observations is that raised ventilatory requirements on exercise may be associated with a variety of cardiac disorders in which it is frequently difficult to define a common pattern of hæmodynamic disturbances. For this reason we are reluctant to offer any suggestion as to the physiological basis of an increase in ventilatory requirements, particularly in view of the obvious limitations of our own data and the number and complexity of factors influencing exercise ventilation, especially in patients with cardiac disease. On the other hand, our experience provides sufficient justification, taking an empirical view for the present, for the routine use of a simple exercise test such as that described in the objective and quantitative assessment of disability.

\section{SUMMARY}

A standardized exercise test was used in 163 patients with heart disease. There was a significant correlation between the clinical grading of disability and ventilatory requirements for exercise $\left(\mathrm{SV}_{300}\right)$. In the more disabled patients, notably those with mitral valve disease, we noted some impairment of ventilatory capacity which was obstructive as well as restrictive in type. A simple exercise test with measurement of exercise ventilation proved a useful measure in the assessment of patients with cardiac disease.

We are indebted to Miss Kathleen King and to Miss Nancy Rogers for technical assistance.

\section{REFERENCES}

Campbell, M. (1934). The respiratory exchange during exercise in heart disease. Quart. J. Med., (n.s.), 3, 369.

Friedman, B. L., Macias, J. de J., and Yu, P. N. (1959). Pulmonary function studies in patients with mitral stenosis. Amer. Rev. Tuberc., 79, 265.

Gandevia, B. (1962). Pulmonary ventilation on exercise and the factors affecting a simple standardized exercise test. Amer. Rev. resp. Dis., 85, 378.

- and Rogers, N. (1963). The effect of a bronchodilator aerosol on ventilatory capacity in patients with chronic pulmonary and cardiac diseases. Brit. med. J. In the press.

Hugh-Jones, P. (1952). A simple standard exercise test and its use for measuring exertion dyspnœa. Brit. med. $J ., 1,65$.

Stock, J. P. P., and Kennedy, M. C. S. (1953). The quantitative assessment of disability in mitral stenosis. Lancet, $2,5$.

Wynt and (1959). Ventilatory cost of exercise before and after mitral valvotomy. Thorax, $14,238$.

Wyndham, C. H., and Ward J. S. (1957). An assessment of the exercise capacity of cardiac patients. Circulation, $16,384$. 